\title{
ERDOSTEINE: AN EFFECTIVE ANTIOXIDANT FOR PROTECTING COMPLETE FREUND'S ADJUVANT INDUCED ARTHRITIS IN RATS
}

\author{
BANYLLA SYNMON ${ }^{1}$, SANHATIDUTTA ROY ${ }^{1}$, SUTAPA BISWAS MAJEE ${ }^{1}$, MEGHNA PAUL $^{1}$, SANDIPAN DASGUPTA ${ }^{2 *}$ \\ ${ }^{1}$ Department of Pharmaceutical Technology, NSHM Knowledge Campus, Kolkata Group of Institutions, Kolkata, West Bengal, India. \\ ${ }^{2}$ Department of Pharmaceutical Science and Technology, Maulana Abul Kalam Azad University of Technology, Haringhata, Nadia, India, \\ Email: sandipan.dasgupta21@gmail.com
}

Received: 26 May 2021, Revised and Accepted: 16 September 2021

ABSTRACT

Objective: The objective of this study was to evaluate the protective effect of Erdosteine on complete freund's adjuvant (CFA) induced arthritic rats.

Methods: Wistar Albino rats of 100-250 g were divided into five groups $(n=6)$ and administered with 0.1 ml of CFA subcutaneously into the left hind paw except the negative control group. The standard group received methotrexate (MTX) $0.075 \mathrm{mg} / \mathrm{kg}$ body weight orally. Besides, the test groups received Erdosteine orally at a dose $10 \mathrm{mg} / \mathrm{kg}$ and $20 \mathrm{mg} / \mathrm{kg}$ bodyweight for 12 days. The changes in body weight, paw volume, hematological parameters, radiographical, and histological findings were the indicators to evaluate the efficacy of the test product.

Discussion: Significant change in the body weight, paw volume, radiographical, hematological, and histological parameters were observed which supports the remarkable reduction of the arthritic development in the standard and test groups compared to the untreated group. However, the test group (Erdosteine) with the dose $20 \mathrm{mg} / \mathrm{kg}$ shows to be more potent than the test group (Erdosteine) with a dose $10 \mathrm{mg} / \mathrm{kg}$ and the standard group (MTX) to reduce the arthritic effect.

Results: The test group with $20 \mathrm{mg} / \mathrm{kg}$ Erdosteine showed much better outcome than the standard group at significant (p<0.05). Therefore, Erdosteine acting as an anti-inflammatory and anti-oxidant is effective at a dose $20 \mathrm{mg} / \mathrm{kg}$ in treating the progression of rheumatoid arthritis in rats.

Keywords: Erdosteine, Artharitis, CFA, Methotrexate.

(C) 2021 The Authors. Published by Innovare Academic Sciences Pvt Ltd. This is an open access article under the CC BY license (http://creativecommons.org/ licenses/by/4.0/) DOI: http://dx.doi.org/10.22159/ajpcr.2021v14i10.42635. Journal homepage: https://innovareacademics.in/journals/index.php/ajpcr

\section{INTRODUCTION}

Rheumatoid arthritis (RA) is a chronic inflammatory disease that affects a large number of people throughout the world [1]. It is characterized by angiogenesis and micro-vascular lesions leading to the infiltration of a variety of inflammatory cells into the joint causing swelling, stiffness, and pain which finally leads to substantial loss of functioning and mobility in its advanced stages. The synovial membrane becomes highly vascularized, synovial fibroblasts proliferate, and inflammatory cells release numerous cytokines and growth factors into the joint [2]. The prevalence of RA varies between $0.3 \%$ and $1 \%$ worldwide and is more common in developed countries. In India, the prevalence of RA was reported to be $0.75 \%$ in the adult population [3]. It is rare in men under 30 years and prevalent in the geriatric population. In women, the incidence rises progressively from about 25 years of age to a broad peak during 45-75 years [4].

It is well established now that free radicals/reactive oxygen species play an important role in inflammation [5]. Control of inflammation is the key to slow down or prevent disease progression as well as manage symptoms of RA. Thus, it is an approach to treat RA by combating those reactive oxygen species with a compound having potent antioxidant activity along with traditional anti-arthritic effect [6]. The treatment is aimed to relieve pain, inflammation, and maintain joint function [7].

Methotrexate (MTX) is prescribed as monotherapy or in combination with other synthetic disease-modifying anti-rheumatic drugs (DMARDs) [8]. Hendawy et al. 2015, reported that MTX is considered by many rheumatologists to be the most important and useful DMARDs and is often considered as the first line of treatment [9]. It is most active in the developing adjuvant model where the opportunity exists to dose it for a longer period (15 days). The ED50 doses are generally $0.06-0.075 \mathrm{mg} / \mathrm{kg} /$ day [10] Therefore, in this study MTX was used as a standard drug.

IUPAC name - 2-[2-oxo-2-[(2-oxothiolan-3-yl) amino]ethyl] sulfanylacetic acid

Erdosteine is a thiol derivative of the same class as acetylcysteine [11] developed for the treatment of chronic obstructive bronchitis. Erdosteine produces an active metabolite (Met 1) which was shown to produce antioxidant effects due to the presence of an SH group [12]. Its mechanism of action is its ability to inhibit some inflammatory mediators and some pro-inflammatory cytokines that are specifically involved in oxidative stress [12]. Based on its free radical scavenging activity, its protective effects against oxidant-induced tissue damage have been demonstrated in various inflammation models [13].

The study rationale is rooted on the fact that the test drug (Erdosteine) which produces low incidence of adverse events $[14,15]$ and prevents the accumulation of free radicals [16] in the body can be used as a potential agent in RA.

\section{METHODS}

Drugs and chemicals

Complete Freund's adjuvant (CFA) and Erdosteine (test drug) were obtained from Sigma-Aldrich Chemicals, Mumbai. MTX was purchased from Ipca Laboratories Ltd, Mumbai, and used as a standard drug. Erdosteine is a white, microcrystalline powder slightly soluble in water, ethanol, methanol, and acetone. It is soluble in $20 \mathrm{mg} / \mathrm{ml}$ Dimethyl sulfoxide (DMSO) and since it is acidic, it is made neutral by adding $\mathrm{NaHCO}_{3}$ Fig. 1. All other chemicals and solvents were of the highest grade commercially available. 
Animals

Thirty adult Wistar albino rats, weighing 100-250 g were obtained from the Central Animal House, NSHM College of Pharmaceutical Technology, acclimatized for 7 days with a 12-h light/dark cycle. In each cage, five animals were housed with free access to commercial food pellet and water ad libitum. The protocol and the facility were maintained according to the guidelines provided by the Institutional Animal Ethical Committee, where all the animals under study were housed in an air-conditioned room $23 \pm 1^{\circ} \mathrm{C}$ and $50 \%$ humidity with a controlled. The animals were acclimatized in clean cage provided with husk bedding for 5 weeks before the study. The procedures throughout the study were carried out as per the guidelines of the Committee for the Purpose of Control and Supervision of Experiments on Animals.

\section{Acute oral toxicity study}

An acute oral toxicity study was carried out using female Wistar rats according to the Organization for Economic Co-operation and Development guidelines 423. A total of 6 female rats were used, 3 for the control group (Group A) and 3 for the test group (Group B). Drug was administered orally to overnight fasted rat sat a volume of $1 \mathrm{ml} / 100 \mathrm{~g}$ body weight. Erdosteine was dissolved in DMSO and was administered at a single dose of $2000 \mathrm{mg} / \mathrm{kg}$ [17] in Group B and tap water was administered to (Fig. 2) Group A and food was withheld for another $3 \mathrm{~h}$. They were observed continuously for $4 \mathrm{~h}$ for behavioral and autonomic profiles and regularly for the first critical $24 \mathrm{~h}$ and daily for a total of 14 days for any lethality. It was observed that none of the animals died at a dose of $2000 \mathrm{mg} / \mathrm{kg}$ body weight. Hence, one hundredth $\left(1 / 100^{\mathrm{th}}\right)$ cut-off dose (i.e. $20 \mathrm{mg} / \mathrm{kg}$ ) was selected for the subsequent study.

\section{Experimental procedure}

Thirty albino rats were randomly divided into five groups and were treated for 12 days and observed for 21 days. All the groups received $0.1 \mathrm{ml}$ of CFA $(10 \mathrm{mg} / \mathrm{ml})$ in the left hind footpad except the negative control group of animals. Group 1, the negative control received only $5 \mathrm{ml} / \mathrm{kg} 0.9 \% \mathrm{w} / \mathrm{v}$ saline solution orally. Group 2, the positive control group received no test drug and group 3 animals were administered with standard MTX at a dose of $0.075 \mathrm{mg} / \mathrm{kg}$ body weight. Similarly, group 4 and group 5 rodents were administered with test drug Erdosteine at a dose of $10 \mathrm{mg} / \mathrm{kg}$ and $20 \mathrm{mg} / \mathrm{kg}$ body weight respectively. The time of adjuvant injection was referred to as day zero and treatment was initiated from day one and continued till the $12^{\text {th }}$ day. The body weight and left hind paw volume of the animals were recorded consecutively on the $1^{\text {st }}, 5^{\text {th }}, 10^{\text {th }}, 15^{\text {th }}$, and $20^{\text {th }}$ day of experimentation $[18,19]$. The percentage inhibition of left paw edema was calculated by the following formula:

$$
\% \text { Inhibition }=(\mathrm{VC}-\mathrm{VT}) \times 100 / \mathrm{VC}
$$

Where, $\mathrm{VC}=$ Paw volume of control group, VT = Paw edema volume of the test/standard group.

On the $19^{\text {th }}$ day of experimentation, all the affected paws of the animals were photo radiographed to observe the soft tissue swelling and the bone space. On the $20^{\text {th }}$ day of experimentation, the blood was collected from each group for hematological investigation and half of the population from each group were sacrificed, left leg was amputated at knee joints and were sent for histopathological evaluation [18,19].

The tissue samples of the tibiotarsal bone were stored in 10\% Neutral Buffered Formalin. The bones were then decalcified by keeping in 5\% Formic acid for 4-5 days. The histopathological tissue sections were sliced, stained with Hematoxylin-Eosin stain, and fixed on the slides and they were observed under a fluorescence microscope (OLYMPUS CX 21i TR) attached to a camera (OLYMPUS LC 30) [18].

\section{RESULTS}

\section{Body weight}

The graph Fig. 3 shows a quantitative change in the body weight of animals in each group. After induction of CFA there was a drastic decline<smiles>O=C(O)CSCC(=O)NC1CCSC1=O</smiles>

Fig. 1: Chemical structure of erdosteine<smiles>O=C(O)CSCC(=O)NC(CCS)C(=O)O</smiles>

Fig. 2: Erdosteine- metabolite 1

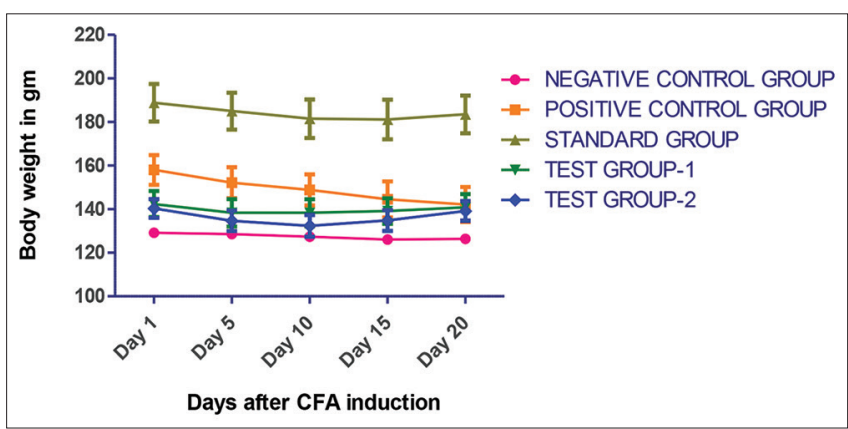

Fig. 3: Change in the body weight. Significant change in the body weight of Methotrexate and Erdosteine treated group. $n=6$, values are expressed as mean $\pm \mathrm{SEM}$, Tukey. Comparison of all parameters

of the control group with standard and test group were done, Non-significant $(p>0.05)$ and significant $(p<0.05)$

in the body weight on day 10 , which elevated due to the administration of the drugs (standard and test drug). However, no significant difference was found in the body weight between the two test groups administered with $10 \mathrm{mg} / \mathrm{kg}$ and $20 \mathrm{mg} / \mathrm{kg}$ of test drug. However, a significant difference between standard and group 5 (test drug $20 \mathrm{mg} / \mathrm{kg}$ ) was found $(\mathrm{p}<0.05)$.

\section{Paw volume}

Fig. 4 clearly indicates maximum swelling in the paw during 5-10 days post-administration of CFA. However, reduction in the paw volume was seen during days 10-20 which indicated decrease in the inflammation. There was a significant decrease in the hind paw volume of all the drug-treated groups compared to the positive control group. Furthermore, substantial design in paw volume was observe in test group 2 compared to the standard group and test group 1 . Table 1 represents mean and percent inhibition of paw volume. Percent Inhibition of arthritis increased in the standard and in both the test groups. However, better outcome was observed in test group 2 (Fig. 5). Tukey's comparison of the data shows significant difference between the groups.

\section{Haematological and biochemical estimation}

The hemoglobin and RBC levels decreased in the positive control group which indicates that the induced arthritic rats were anemic. However, when compared with the standard and test groups their levels were normal post-induction. WBC drastically multiplied in number in positive control group indicating elevated inflammation in the hind paws. However, in the standard and test group, WBC count become normal 
on day 21. Serum albumin is also one that can act as an inflammatory marker. Previous studies showed that decrease in the albumin level may be correlated with alteration in the RA condition related to the augmented level of pro-inflammatory cytokines [21]. Lower levels of serum albumin correspond to higher levels of inflammatory activity, as the albumin accumulates in the inflamed joint. The ESR value of the inflamed paws of arthritis rats in the positive control group was very high compared to the groups being treated with MTX and Erdosteine (Table 2). Besides, there is a significant change in the RF in all the drug-treated groups and in positive control. It was observed that the untreated group had a high level of RF than the groups treated with MTX and Erdosteine. Eventually, the test group being treated with

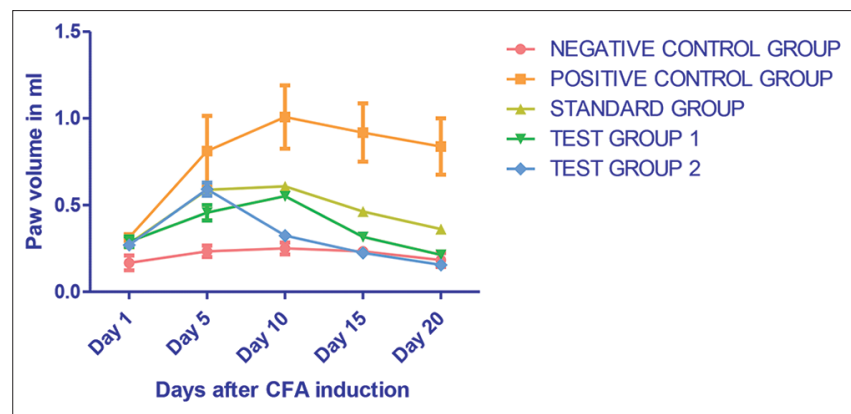

Fig. 4: Change in Paw volume. Reduction of the paw volume after drug treatment on the arthritis-induced Albino rats. $n=6$ rats in each group, values are expressed as mean \pm SEM, Tukey.

Comparison of all parameters of the control group with standard and test group, Non-significant $(p>0.05)$, Significant $(p<0.05)$

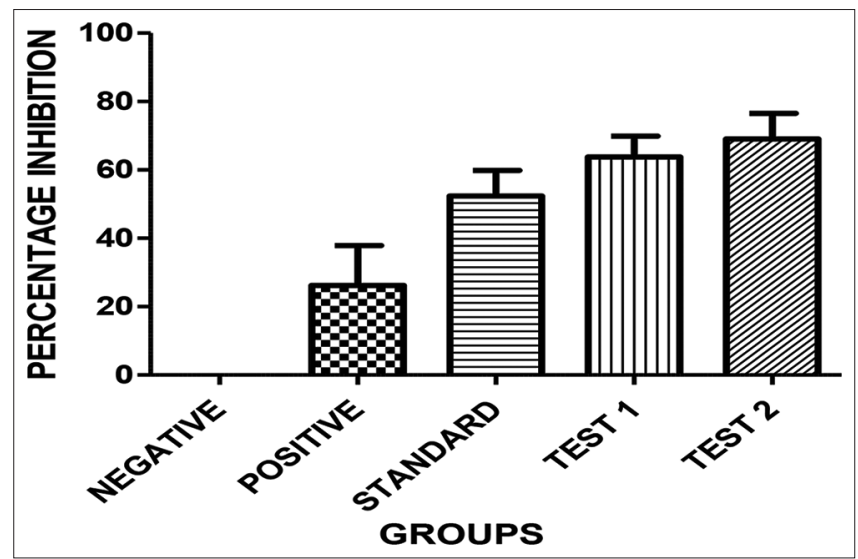

Fig. 5: \% inhibition of paw volume using one way ANOVA, $n=6$ rats in each group, values are expressed as mean \pm SEM
$20 \mathrm{mg} / \mathrm{kg}$ Erdosteine shows better result than the standard and test group.

\section{Radiographical evaluation}

Radiographs were evaluated to study the clinical features of the adjuvant-induced arthritis in rats. The soft skin thickening and the bone erosion were looked for. Pathological changes were compared between the control and the treatment groups. X-ray of normal rats (Fig. 6a) shows no pathological features, however, that of non-treated arthritic rats (Fig. 6b) shows severe soft tissue swelling (arrow), severe joint swelling, and very narrow joint space. X-ray of arthritic rats treated with MTX (Fig. 6c) at a dose of $0.075 \mathrm{mg} / \mathrm{kg}$ showed moderate soft tissue edema (arrow), moderate joint swelling, and very narrow joint space. Consequential changes were seen in x-rays of Erdosteine treated arthritic rats at a dose of $10 \mathrm{mg} / \mathrm{kg}$ (Fig. 6d) manifesting softtissue edema, mild joint swelling, and moderate narrow joint space and at a dose of $20 \mathrm{mg} / \mathrm{kg}$ (Fig. 6e)showing no soft tissue edema or joint swelling and improved narrow joint space.

From the clinical radiographic features, it was observe that there was an improved prognosis in the groups treated with MTX and Erdosteine compared to the untreated group. Besides, improved treatment outcomes were observed in a dose-dependent manner.

\section{Histopathological evaluation}

Different slides from different groups were observed on the computer screen at a magnification of $10 \times$ and $40 \times$ and the photomicrographs were snapshot.

Photomicrograph of a tissue section of a rat from the Negative Control group showed no sign of inflammation, bone destruction, or inflammatory cells (Fig. 7a). Section of the tissue from the rat paw of the positive control group i.e., non-treated arthritic group, showed massive numbers of inflammatory cells infiltration, pannus formation, bone destruction, and narrow synovial space (Fig. 7b). Similarly, paw section of standard group demonstrates reduced inflammation and improved synovial space. In addition, lesser macrophages and neutrophils infiltration were observed in standard treated group. However, pannus formation and bone destruction were evident in this section (Fig. 7c). Bone destruction and inflammatory cells infiltration were much lesser in this section in test treated group 2 compared to group 1. From the result, it is evident that Erdosteine at a dose of $20 \mathrm{mg} / \mathrm{kg}$ is potent enough to decrease inflammation in RA.

\section{DISCUSSION}

As the etiology behind RA prognosis is not well understood confirmed curative measures are not discovered till date [14]. Current treatments include non-steroidal anti-inflammatory drugs (NSAIDs), DMARDs, and biologics, but none are curative and there is a significant "nonresponder" rate [22]. NSAIDs and DMARDS are associated with adverse

Table 1: Average paw volume and \%inhibition of paw volume of the adjuvant-induced arthritis in Wistar Albino rats

\begin{tabular}{|c|c|c|c|c|c|}
\hline Groups & Day 1 & Day 5 & Day 10 & Day 15 & Day 20 \\
\hline \multicolumn{6}{|c|}{ Negative control } \\
\hline Average & $0.12 \pm 0.11$ & $0.18 \pm 0.06$ & $0.21 \pm 0.05$ & $0.22 \pm 0.06$ & $0.17 \pm 0.06$ \\
\hline \%Inhibition & 0 & 0 & 0 & 0 & 0 \\
\hline \multicolumn{6}{|l|}{ Positive control } \\
\hline Average & $0.33 \pm 0.05$ & $0.64 \pm 0.1$ & $1.01 \pm 0.04$ & $0.88 \pm 0.06$ & $0.85 \pm 0.12$ \\
\hline \%Inhibition & 67 & 36 & 1 & 12 & 15 \\
\hline \multicolumn{6}{|l|}{ Standard group } \\
\hline \%Inhibition & 73 & 32 & 40 & 54 & 63 \\
\hline \multicolumn{6}{|l|}{ Test group 1} \\
\hline Average & $0.29 \pm 0.06$ & $0.45 \pm 0.15$ & $0.55 \pm 0.05$ & $0.31 \pm 0.09$ & $0.21 \pm 0.07$ \\
\hline \%Inhibition & 71 & 55 & 45 & 69 & 79 \\
\hline \multicolumn{6}{|l|}{ Test group 2} \\
\hline Average & $0.27 \pm 0.09$ & $0.59 \pm 0.09$ & $0.32 \pm 0.08$ & $0.22 \pm 0.07$ & $0.15 \pm 0.05$ \\
\hline \%Inhibition & 73 & 41 & 68 & 78 & 85 \\
\hline
\end{tabular}


Table 2: Change in haematological and biochemical evaluation

\begin{tabular}{|c|c|c|c|c|c|c|}
\hline S. No. & Parameters & $\begin{array}{l}\text { Negative } \\
\text { control group }\end{array}$ & $\begin{array}{l}\text { Positive control } \\
\text { group }\end{array}$ & Standard group & $\begin{array}{l}\text { Test group } 1 \\
(10 \mathrm{mg} / \mathrm{kg}) \\
\end{array}$ & $\begin{array}{l}\text { Test group } 2 \\
(20 \mathrm{mg} / \mathrm{kg}) \\
\end{array}$ \\
\hline 1. & Haemoglobin $(\mathrm{g} / \mathrm{dL})$ & $16.1 \pm 5.5$ & $9.7 \pm 2.4$ & $12.8 \pm 4.7$ & $12.5 \pm 4.2$ & $13.8 \pm 3.3$ \\
\hline 2. & Total WBC count $\left(\mathrm{mm}^{3}\right)$ & $7.3 \times 10^{3} \pm 5.4$ & $10.3 \times 10^{3} \pm 4.4$ & $11.6 \times 10^{3} \pm 4.3$ & $8.4 \times 10^{3} \pm 4.6$ & $6.6 \times 10^{3} \pm 5.1$ \\
\hline 3. & Neutrophils $\left(\mathrm{mm}^{3}\right)$ & $2.6 \times 10^{3} \pm 2.6$ & $3.6 \times 10^{3} \pm 2.5$ & $4.6 \times 10^{3} \pm 1.9$ & $1.3 \times 10^{3} \pm 3,2$ & $1.9 \times 10^{3} \pm 2.6$ \\
\hline 4. & Lymphocytes $\left(\mathrm{mm}^{3}\right)$ & $6.8 \times 10^{3} \pm 3.4$ & $6.1 \times 10^{3} \pm 5.6$ & $5.6 \times 10^{3} \pm 4.0$ & $3.7 \times 10^{3} \pm 4.7$ & $4.1 \times 10^{3} \pm 4.6$ \\
\hline 5. & Monocytes $\left(\mathrm{mm}^{3}\right)$ & $0.02 \times 10^{3} \pm 0.02$ & $0.03 \times 10^{3} \pm 0.02$ & $0.03 \times 10^{3} \pm 0.01$ & $0.01 \times 10^{3} \pm 0.01$ & $0.01 \times 10^{3} \pm 0.01$ \\
\hline 6. & Eosinophils $\left(\mathrm{mm}^{3}\right)$ & $0.05 \times 10^{3} \pm 0.03$ & $0.07 \times 10^{3} \pm 0.02$ & $0.04 \times 10^{3} \pm 0.01$ & $0.04 \times 10^{3} \pm 0.02$ & $0.03 \times 10^{3} \pm 0.01$ \\
\hline 7. & Basophils $\left(\mathrm{mm}^{3}\right)$ & $0.01 \times 10^{3}$ & $0.0 \times 10^{3}$ & $0.0 \times 10^{3}$ & $0.0 \times 10^{3}$ & $0.0 \times 10^{3}$ \\
\hline 8. & $\mathrm{RBC}\left(\mathrm{mm}^{3}\right)$ & $7.76 \times 10^{6} \pm 2.1$ & $5.80 \times 10^{6} \pm 1.6$ & $6.1 \times 10^{6} \pm 2.5$ & $6.50 \times 10^{6} \pm 3.2$ & $7.40 \times 10^{6} \pm 2.6$ \\
\hline 9. & $\operatorname{ESR}(\mathrm{mm} / \mathrm{h})$ & $19.3 \pm 1.6$ & $40 \pm 5.5$ & $26.16 \pm 3.2$ & $28 \pm 4.1$ & $23.16 \pm 2.3$ \\
\hline 10. & RA factor $(\mathrm{mIU} / \mathrm{ml})$ & $3.9 \pm 1.6$ & $5.2 \pm 2.6$ & $3.8 \pm 2.2$ & $3.2 \pm 1.5$ & $2.9 \pm 0.7$ \\
\hline 11. & Albumin $(\mathrm{g} / \mathrm{dL})$ & $3.8 \pm 1.8$ & $3.2 \pm 0.9$ & $3.6 \pm 0.5$ & $3.7 \pm 1.2$ & $3.8 \pm 1.4$ \\
\hline
\end{tabular}

$\mathrm{n}=6$, values were expressed as mean \pm SEM, Tukey. Comparison of all parameters of control group with standard and test group, Non significant (p $>0.05$ ), ${ }^{*}$ Significant $(\mathrm{p}<0.05)$. RA: Rheumatoid arthritis.

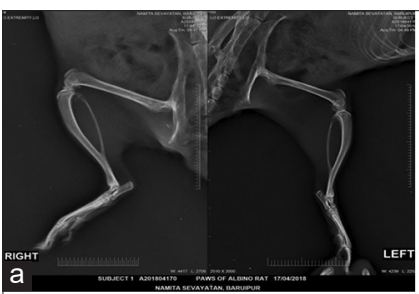

Negative control group

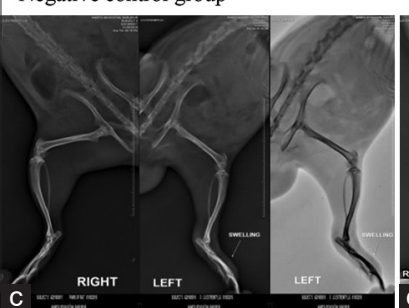

Standard group

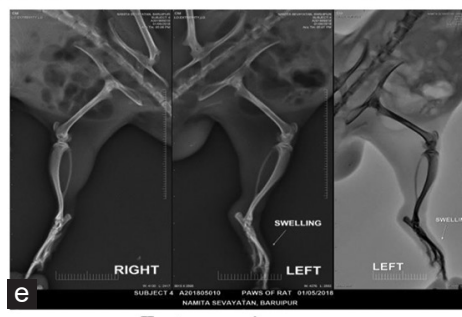

Test group 2

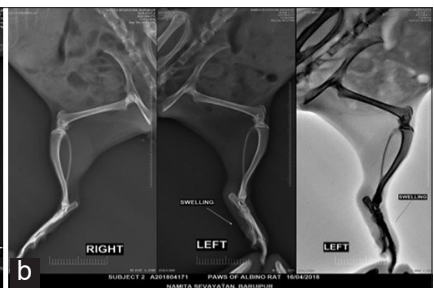

Positive control group

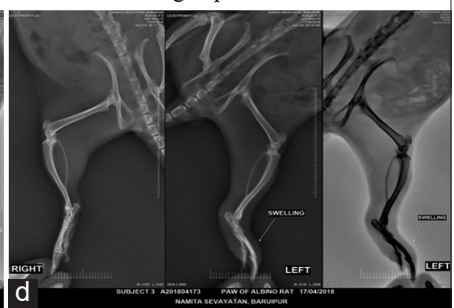

Test group 1

Fig. 6: Radiographical images of paws of the rats under study

(a) X-ray image of a rat without CFA induced, treated with saline

(b) X-ray figure of a rat induced with CFA treated with saline;

(c) X-ray of rat induced with CFA and treated with methotrexate;

(d) X-ray image of rat induced with CFA treated with $10 \mathrm{mg} / \mathrm{kg}$

Erdosteine; (e) X-ray of rat induced with CFA treated with

20 mg/kg Erdosteine. CFA: Complete freund's adjuvant

effects [9]. Because of this reason, many patients and practitioners are seeking alternative approaches for providing an effective cure for the treatment of disease and to overcome the serious drawbacks such as gastrointestinal bleeding and bone loss. Hence, there is an urgent need to find safer compounds for the management of RA [11].

Rat adjuvant arthritis is an experimental model of polyarthritis which has been widely used for preclinical testing of numerous anti-arthritic agents which are either under preclinical or clinical investigation or are currently used as therapeutics in this disease [10]. It has been experimentally proved that adjuvant-induced arthritis in rat mimics the pathological, immunological, and clinical significance of human RA [20].
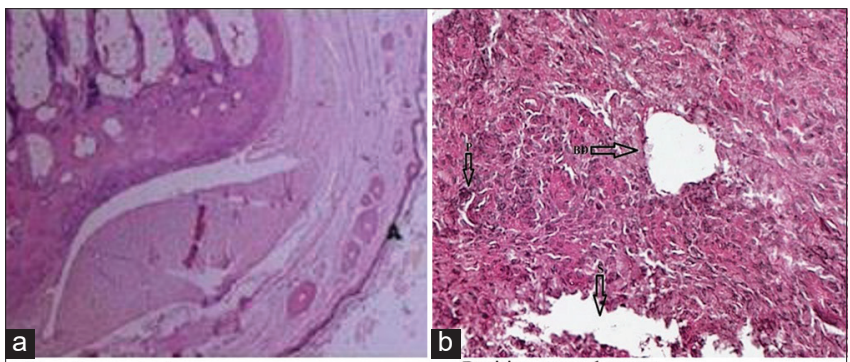

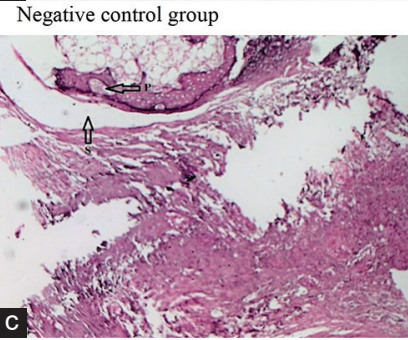

Standard group
Positive control group

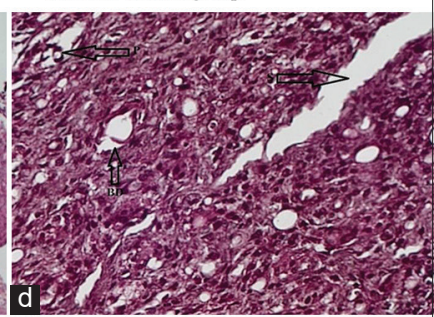

Test group 1

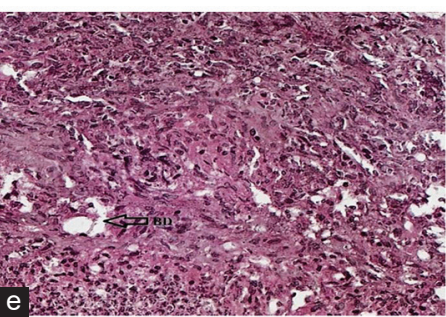

Test group 2

Fig. 7: Sections of tibiotarsal tissue sample of the rats for histological evaluation at $10 \times$ and $40 \times$. (a) Negative control group (b) Positive control group without treatment; Sections of tibiotarsal tissue sample of the rats for histological evaluation at $10 \times$ and $40 \times$. (c) Standard group treated with $0.075 \mathrm{mg} / \mathrm{kg}$ Methotrexate; (d) Test group 1 treated with $10 \mathrm{mg} / \mathrm{kg}$ Erdosteine;

(e) Test group 2 treated with $20 \mathrm{mg} / \mathrm{kg}$ Erdosteine

There was a significant difference in the result between the control and treatment groups in this study. It was observed that the body weight of the animals being treated started to improve on Day 10 along the course of the treatment but no improvement was seen in the untreated group of rats. Patil et al. suggest that the decrease in body weight during inflammation is due to deficient absorption of nutrients through the intestine [23]. In this study, standard group treated with MTX and the group treated with Erdosteine $20 \mathrm{mg} / \mathrm{kg}$ had a significant change $\mathrm{p}<0.05$ proving the decrease in inflammation. 


\section{CONCLUSION}

In this study, treatment with MTX and Erdosteine as standard and test drug, respectively, in the arthritis induced groups recede the inflammation significantly. Furthermore, Erdosteine given at a dose of $20 \mathrm{mg} / \mathrm{kg}$ was more effective compared to the standard drug. The results, therefore, supports that the test drug, Erdosteine can be a potential anti-inflammatory and anti-oxidant lead for the treatment of RA.

\section{ACKNOWLEDGMENT}

We are thankful to NSHM Knowledge Campus and Maulana Abul Kalam Azad University of Technology, West Bengal for providing us the facilities required for this research work.

\section{CONFLICT OF INTEREST}

There was no conflict of interest among the authors.

\section{REFERENCES}

1. Ren K, Dusad A, Dong R, Quan L. Albumin as a delivery carrier for rheumatoid arthritis. J Nanomed Nanotechol 2013;4:176

2. Roger W, Clive E. Clinical Pharmacy and Therapeutics London. $3^{\text {rd }}$ ed. London, United Kingdom: Churchill Livingstone; 2003. p. 791-3.

3. Snekhalatha U, Anburajan M, Venkatraman B, Menaka M. Evaluation of complete Freund's adjuvant-induced arthritis in a Wistar rat model. Z Rheumatol 2013;72:375-82.

4. Greene RJ, Harris ND. Pathology and Therapeutics for Pharmacists: A Basis for Clinical Pharmacy Practice. $3^{\text {rd }}$ ed. London: Pharmaceutical Press; 2008.

5. Mahajan A, Tandon VR. Antioxidants and rheumatoid arthritis. J Indian Rheumatol Assoc 2004:12:4:139-42.

6. Roy S, Sannigrahi S, Ghosh B, Pusp P, Roy T. Combination therapy of dexamethasone with epigallocatechin enhances tibiotarsal bone articulation and modulates oxidative status correlates with cartilage cytokines expression in the early phase of experimental arthritis. Eur J Pharmacol 2013;698:444-54.

7. Dipiro JT, Talbert RL, Yee GC, Matzke GR, Wells BG, Posey LM. Pharmacotherapy: A Pathophysiologic Approach. $7^{\text {th }}$ ed. New York: McGraw-Hill Medical; 2014

8. Hansen SM. Rheumatoid arthritis and work. Faculty of Health and
Medical Science, University of Copenhagen, Graduate School at the Faculty of Health and Medical Sciences. Copenhagen: University of Copenhagen; 2016

9. Hendawy OM, Ahmed WM, Abosaif AA, Mahmoud FA. Effect of atorvastatin and Vitamin D on Freund's adjuvant-induced rheumatoid arthritis in rat. J Bioequiv Availab 2015;7:090-4.

10. Bendele A. Animal models of rheumatoid arthritis. J Musculoskelet Neuronal Interact 2001;1:377-85

11. Wilsher M. Erdosteine: A viewpoint. Drugs 1996;52:882.

12. Dal Negro RW. Erdosteine: Antitussive and anti-inflammatory effects. Lung 2008;186:70-3.

13. Sener G, Aksoy H, Sehirli O, Yüksel M, Aral C, Gedik N, et al. Erdosteine prevents colonic inflammation through its antioxidant and free radical scavenging activities. Dig Dis Sci 2007;52:2122-32.

14. Hoza J, Salzman R, Starek I, Schalek P, Kellnerova R. Efficacy and safety of erdosteine in the treatment of chronic rhinosinusitis with nasal polyposis-a pilot study. Rhinology 2013;51:323-7.

15. Yagmurca M, Fadillioglu E, Erdogan H, Ucar M, Sogut S, Irmak MK. Erdosteine prevents doxorubicin-induced cardiotoxicity in rats. Pharmacol Res 2003;48:377-82.

16. Moretti M, Marchioni CF. An overview of erdosteine antioxidant activity in experimental research. Pharmacol Res 2007;55:249-54.

17. Kala C, Ali SS, Abid M, Sharma US, Khan NA. Evaluation of in-vivo antiarthritic potential of methanolic extract of Cheilocostus speciosus rhizome. J Appl Pharm Sci 2015;5:46-53.

18. Dasgupta S, Ghosh SK, Ray S, Mazumder B. Solid lipid nanoparticles (SLNs) gels for topical delivery of aceclofenac in vitro and in vivo evaluation. Curr Drug Deliv 2013;10:656-66.

19. Dasgupta S, Ghosh SK, Ray S, Kaurav SS, Mazumder B. In vitro in vivo studies on lornoxicam loaded nanoemulsion gels for topical application. Curr Drug Deliv 2014;11:132-8.

20. Hasan UH, Uttra AM, Rasool S. Evaluation of in vitro and in vivo antiarthritic potential of Berberis calliobotrys. Bangladesh J Pharmacol 2015;10:807-19.

21. Rohmah RN, Widjajanto E, Fatchiyah F. Protective effect of CSN1S2 protein of goat milk on ileum microstructure and inflammation in ratCFA-induced rheumatoid arthritis. Asian Pac J Trop Dis 2015;5:564-8.

22. Vandever LA. How are Rheumatoid Arthritis and Anaemia Connected, Healthline Newsletter; 2018. Available from: https://www.healthline. com/health/rheumatoid-arthritis-and-anemia. [Last accessed on 2021 Sep 26].

23. Patil KS, Suryavanshi J. Effect of Celastrus paniculatus Willd. Seed on adjuvant induced arthritis in rats. Pharmacogn Mag 2007;3:177. 